\title{
Hegel en Lacan. Las trampas de lo imaginario y la función del lenguaje en la constitución del sujeto
}

\author{
LUIS MARIANO DE LA MAZA* \\ Pontificia Universidad Católica de Chile (Chile) \\ sdel4@uc.cl
}

Resumen

Este artículo expone la presencia de Hegel en la teoría psicoanalítica de Lacan: en primer lugar, el uso que este último hace de la dialéctica del amo y el esclavo para iluminar la dimensión imaginaria de la conciencia y el deseo, en segundo lugar, la recepción de la concepción hegeliana del lenguaje en conexión con la función simbólica y la constitución de la subjetividad, y finalmente la postura de ambos respecto de la relación entre saber y verdad. Los tres aspectos contribuyen a iluminar la interpretación del concepto de sujeto en Lacan a la luz de la influencia hegeliana.

Palabras claves: Lacan, Hegel, imaginario, autoconciencia, deseo, lenguaje, otro, sujeto, saber, verdad.

\section{Hegel in Lacan. The traps of the imaginary and the function of language in the constitution of the subject}

\begin{abstract}
This article exposes the presence of Hegel in the psychoanalytic theory of Lacan: first, the use that the latter makes of the dialectic of the master and the slave to illuminate the imaginary dimension of consciousness and desire, secondly, the reception of the Hegelian conception of language in connection with the symbolic function and the constitution of subjectivity, and finally the position of both with respect to the relationship between knowledge and truth. The three aspects contribute to illuminate the interpretation of the concept of subject in Lacan in light of the Hegelian influence.
\end{abstract}

Keywords: Lacan, Hegel, imaginary, self-consciousness, desire, language, other, subject, knowledge, truth.

* Profesor Titular de la Pontificia Universidad Católica de Chile. Su docencia e investigación gira en torno al idealismo alemán, la fenomenología y la hermenéutica; y la antropología filosófica, la ética y la filosofía social. Entre sus publicaciones cabe mencionar los libros Knoten und Bund. Zum Verbältnis von Logik, Geschichte und Religion in Hegels Phänomenologie des Geistes (1998); Lógica, Metafísica, Fenomenología. La Fenomenología del Espiritu de Hegel como introducción a la Filosofía especulativa (2004); asimismo los artículos "Voluntad, razón práctica y reconocimiento en el cruce de Hegel y Ricoeur" (2014), "Sobre el espíritu en Hegel y Edith Stein" (2015), "La reformulación de la fenomenología del espíritu en la Enciclopedia de las ciencias filosóficas de Hegel” (2017).

Este trabajo forma parte de un proyecto de investigación financiado por Fondecyt $\left(\mathrm{N}^{\circ} 1100815\right)$. 
El propósito de este artículo es doble. Por una parte, se trata de examinar la fuente hegeliana de algunos importantes conceptos de la teoría psicoanalítica de Lacan, como por ejemplo los conceptos de amo, deseo, Otro. Por otra parte, quiere contribuir a una interpretación del concepto de sujeto en Lacan a la luz de la influencia hegeliana. No se busca estudiar a Lacan desde el punto de vista de la praxis analítica, sino más bien desde algunos de los conceptos y presupuestos de dicha praxis. Ello se justifica en gran medida por la importancia que el propio Lacan asignara a su diálogo con la filosofía, y la dedicación a Hegel en particular. La razón para recurrir a Hegel no obedece a un interés por interpretar fielmente su pensamiento: "[...] nuestro uso de la fenomenología de Hegel no implicaba ninguna fidelidad al sistema [...]" (Lacan, 1975: 916). En general, no puede decirse que Lacan tuviera una inclinación a rendir homenaje a los filósofos clásicos por su condición de tales. Más bien saca provecho, con fines didácticos, del intenso clima intelectual que significó la difusión del pensamiento de Hegel en la cultura francesa a partir de los años treinta del siglo pasado gracias al impulso de la interpretación de Alexander Kojève, quien puso en órbita temas con los que indudablemente el psicoanálisis tiene una afinidad natural, y en especial los relativos a la subversión freudiana del sujeto (Lacan, 1975: 774). De hecho, el título general con el cual Lacan presenta, el año 1966, el inicio de su enseñanza respecto al psicoanálisis y el conjunto del pensamiento contemporáneo es "Del sujeto por fin cuestionado". Desde este punto de vista, la investigación de estos temas no posee meramente un interés propedéutico, sino una importancia intrínseca, y el aporte de Hegel, mediado por Kojève y por Hyppolite, tiene también un valor constitutivo.

Hegel tiene una triple presencia en Lacan. Por una parte, representa la dimensión negativa, imaginaria de la conciencia y sus trampas enmascaradoras de la verdad. Por otra parte, se vincula con lo simbólico como lugar de la verdad través de su referencia al Otro con mayúscula, y al lenguaje. $Y$ finalmente se relaciona con una cierta concepción del saber que aspira a identificarse con lo real, pero que, en Lacan, a diferencia de Hegel, nunca puede llegar a ser más que una verdad a medias. Cruzando transversalmente estas tres cuestiones se encuentra el tema de la subjetividad humana, que en Lacan experimenta una profunda subversión respecto de las concepciones tradicionales.

\section{LAS TRAMPAS DE LO IMAGINARIO}

Según Lacan, la técnica psicoanalítica no puede desconocer los elementos estructurales de la fenomenología hegeliana como la dialéctica del 
amo y el esclavo, el alma bella y la ley del corazón, y, en general, la identidad de lo particular y lo universal. Pero estos elementos reciben su significación más propia con el descubrimiento freudiano de que el proceso que existe tras la dialéctica de la Fenomenología del espiritu "no alcanza auténticamente al sujeto sino descentrándolo de la conciencia de sî" (Lacan, 1971: 281).

La excentricidad del sujeto con respecto al yo, es decir que el núcleo de nuestro ser no coincide con el yo o con la conciencia que el sujeto tiene de sí mismo, constituye, según Lacan, el sentido esencial de la experiencia freudiana que la conecta con la Fenomenología:

El yo del que hablamos es absolutamente imposible de distinguir de las captaciones imaginarias que lo constituyen de cabo a rabo, en su génesis como en su estatuto, en su función como en su actualidad, por otro y para otro. Dicho de otra manera, la dialéctica que sostiene nuestra experiencia, situándose al nivel más envolvente de la eficacia del sujeto, nos obliga a comprender el yo de punta a punta en el movimiento de enajenación progresiva en que se constituye la conciencia de sí en la fenomenología de Hegel. (Lacan, 1971: 359)

El yo es un objeto particular en el interior de la experiencia del sujeto, que cumple una función específica, a la que llama la función imaginaria. Esta función se vincula en Lacan con el fenómeno clínico de la resistencia.

La resistencia está asociada a lo que Lacan denomina "el nudo inaugural del drama analítico" (1971: 100), a saber, el fenómeno de la transferencia negativa. Se trata de la hostilidad agresiva que aparece en el paciente analizado frente a la intención terapéutica del analista. La resistencia es el obstáculo en la relación del yo del paciente y el yo del analista. Lacan se apoya en el concepto del yo formulado por Freud en su teoría del narcisismo de 1911, y atribuye el obstáculo propio de la resistencia a lo imaginario, obstáculo que no se encuentra únicamente en el analizado, sino también en el analista, en la medida que éste no se sitúa en la posición adecuada respecto del paciente.

En relación al concepto de la resistencia, vale la pena destacar las referencias explícitas a la relación entre dicho concepto y la Verneinung (negación o denegación) de la que habla Freud. Lacan solicita a Jean Hyppolite, quien fuera, entre otras cosas, traductor de la Fenomenología del espiritu al francés, un comentario sobre este concepto de la Verneinung, comentario que el mismo Lacan introduce y contesta en el Seminario 1 sobre Los escritos técnicos de Freud de 1953-4, y que reelabora por escrito y reproduce en sus Escritos. Tanto Hyppolite como Lacan hacen explícita referencia a la conexión de la Verneinung con el concepto lógico- metodológico central de la 
Aufhebung en Hegel, que significa superar, en el doble sentido de negar y conservar lo negado. En Freud, la denegación es un modo de presentar lo que se es bajo el modo de no serlo; es una Aufhebung de la represión, sin aceptar lo reprimido (Lacan, 1975: 860ss.). El comentario de Hyppolite le permite a Lacan recordar que la condición para que una cosa exista para un sujeto es la existencia de una afirmación primera, no una simple negación de la negación. La falta de esta afirmación primera corresponde a la forclusión (Verwerfung), caracterizada como el no querer saber nada sobre algo; por lo tanto, todo ocurre como si la cosa en cuestión no existiera para el sujeto. A la afirmación primera (Bejahung) de Freud, Lacan la denomina "simbolización primitiva", una simbolización en la que el sujeto se encuentra atrapado desde el principio. Esta afirmación inaugural, que es inconsciente, no puede ser retomada y reafirmada conscientemente sino mediante la negación de su negación. De donde surge la diferencia entre aquello que puede reaparecer en la historia del sujeto y aquello que está verworfen y excluido para siempre de esa historia (Lacan, 1971: 372). La forclusión conduce a la psicosis, mientras que la represión (Verdrängung) da cuenta de la neurosis.

En este contexto la dialéctica del amo y del esclavo es interpretada en un sentido negativo, como un callejón del que hay que tratar de salir. Pero esta salida no puede consistir en llevar a la conciencia lo negado, pues la conciencia pertenece justamente al registro de lo imaginario. El problema consiste más bien en poder liberar el mensaje inconsciente, que se encuentra en el plano de la función simbólica del lenguaje. Lacan distingue el "ideal del yo", que se sitúa en el registro de lo simbólico, del "yo ideal", que pertenece al registro de lo imaginario. La dialéctica del amo y del esclavo rige el ámbito del "yo ideal", que es también el lugar donde el analizado pone al analista. Pero es justamente desde ese lugar que se organizan las ilusiones y las resistencias. En cambio "el ideal del yo" remite al ámbito del intercambio simbólico que vincula entre sí a los seres humanos: "[...] el símbolo da a luz seres inteligentes, como dice Hegel" (1981a: 215. Probablemente Lacan alude en este contexto a la Psicología de la Enciclopedia de Hegel (2017b), por ejemplo, los $\int S$ 458-459).

El ideal del yo es el otro en tanto que habla, mientras que el yo ideal se define por la imagen del semejante que reemplaza la imagen del cuerpo propio como matriz en torno a la cual se organiza la identidad del sujeto. Aquí se pone en juego el registro de lo imaginario, de índole esencialmente visual, y al que Lacan asocia al desarrollo del "estadio del espejo". Con este concepto se refiere al período que abarca entre los seis y los dieciocho meses en el que el niño "reconoce" por primera vez su propia imagen en 
un espejo, haciendo una conexión entre su motricidad interna y los movimientos que percibe ante él. Para Lacan, este estadio marca una brecha fundamental e insuperable entre el sujeto y su imagen:

[...] el punto importante es que esta forma sitúa la instancia del yo, aun desde antes de su determinación social, en una línea de ficción, irreductible para siempre por el individuo solo; o más bien, que solo asintóticamente tocará el devenir del sujeto, cualquiera que sea el éxito de las síntesis dialécticas por medio de las cuales tiene que resolver en cuanto yo [je] su discordancia con respecto a su propia realidad. (1971: 87)

Durante este período, el niño todavía no puede distinguir su propia forma de las de los demás. Vive en un ambiente afectivo de cuerpos indiferenciados, sin centro de referencia o punto de vista privilegiado. El niño se identifica con el otro, llora cuando ve caer a otro y al golpear dice haber sido golpeado. Pero en este proceso de formación del yo se encuentra también el origen de la agresividad humana, como resultado de la rivalidad que comienza a establecer con el otro el yo que se configura una identidad rígida que marcará todo su desarrollo mental. Lo imaginario es, entonces, una forma de alienación, pues el sujeto es cautivado por su imagen especular, configurando una espacialidad definida por la relación entre adentro y afuera, continente y contenido, de la que derivará posteriormente la oposición de bueno y malo.

Frente al fenómeno de la resistencia, Lacan señala que es insuficiente cualquier intervención clínica que se apoye en una concepción tradicional del individuo como una totalidad autoconsciente. Por ello sostiene, en el Seminario 2, sobre El yo en la teoría de Freud y en la técnica psicoanalítica, que el aporte original de Freud en relación a Hegel es que Freud salió de los límites de la antropología en los que todavía se encontraba aquél: "Entre Hegel y Freud tenemos el advenimiento de la máquina" (Lacan, 1983: 119). Esto tiene como consecuencia, según Lacan, que Freud puede hablar de la energía, y partir de una concepción del sistema nervioso según el cual éste tiende siempre a retornar a un punto de equilibrio. El cerebro se presenta como una máquina de soñar, en la que reencuentra lo que siempre estaba allí sin ser visto: "es en el nivel de lo más orgánico y lo más simple, de lo más inmediato y lo menos manejable, en el nivel de lo más inconsciente, donde el sentido y la palabra se revelan y desarrollan en su integridad". En otras palabras, "Freud descubre el funcionamiento del símbolo como tal $[\ldots]$, en sus desplazamientos, retruécanos, juegos de palabras, bromas que funcionan por su cuenta en la máquina de soñar" (Lacan, 1983: 121). 
En sus años iniciales, Lacan esperaba que la toma de conciencia de la imagen en la que se enajenó el sujeto, hiciera posible la cura o la eliminación de los síntomas. Pero el Discurso de Roma de 1953 presenta una nueva teoría del análisis, en la que Lacan niega expresamente que baste con reenviar al sujeto a su propia imagen para desenajenarlo. Usa la expresión "palabra vacía" para designar la palabra mediante la que el sujeto reconoce su yo como un objeto, pero no su deseo, es decir no se reconoce a sí mismo. Por lo tanto, el objetivo de la cura ya no es la toma de conciencia especular del yo imaginario, sino reconocer el sujeto del deseo.

\section{EL DESEO DE DESEO}

Para Lacan, el deseo no tiene una finalidad sexual, sino narcisista, es decir no busca la satisfacción sexual, sino el reconocimiento, es el deseo de que se reconozca su deseo. En esta fórmula resuena la lectura kojèviana de la Fenomenología de Hegel en un célebre curso dictado entre 1933-1939 en la École Practique des Hautes Études de París, al cual Lacan asistió, y que tuvo gran repercusión en el pensamiento francés (Labarrière \& Jarczyk, 1996). Según la interpretación de Kojève, la Fenomenología del espiritu expone el proceso por el cual el hombre se constituye a sí mismo como sujeto. Para que haya una existencia verdaderamente humana se requiere autoconciencia, es decir una mismidad humana que se revela cuando el hombre dice "yo". (Kojève, 2013: 209). Ello presupone, en primer lugar, la existencia de una conciencia que conoce el ser de las cosas, el cual se revela a través de la palabra. Pero para que la palabra revele al yo se requiere además el deseo, el cual no está referido simplemente a un ser dado positivamente, sino a un no-ser. En ello consiste la diferencia esencial del hombre con el animal. Desear lo dado, como lo hace el animal, es depender de él; en cambio desear lo que no está dado es liberarse de lo dado y ser autónomo. Por lo tanto, el hombre se hace libre negando activamente lo dado, que incluye su propia realidad natural, por medio de la lucha y el trabajo (Kojève, 2013: 547-550). Lo que desea el deseo humano- afirma Kojèvees el deseo como tal, sin contenido. Por lo tanto, está dirigido hacia otro deseo igualmente negativo, el deseo de otro yo (Kojève, 2013: 53).

La realización de la autoconciencia humana presupone, según esta concepción, la existencia de múltiples deseos intersubjetivos en lucha por el reconocimiento, es decir por hacer prevalecer su deseo o ser dominadores del deseo de los otros. Esta lucha es en un primer momento una lucha de vida o muerte. Pero la lucha por el reconocimiento no puede concluir en la muerte de ninguno de los contrincantes, pues el sobreviviente no podría ser reconocido por un cadáver. Por otra parte, Hegel y Kojève sos- 
tienen que el hombre que es incapaz de poner en peligro su vida para alcanzar fines no inmediatamente vitales, como el puro prestigio, no es verdaderamente libre y humano (Kojève, 2013: 214). La lucha termina cuando una de las dos autoconciencias cede ante la otra, porque no es capaz de sobreponerse al instinto de conservación, haciéndose entonces esclava de aquella otra que desprecia la muerte y que se convierte, por lo mismo, en amo dominador de la autoconciencia vencida, poniéndola a su servicio. Según Kojève, toda la historia es una historia de la interacción entre amos que luchan y esclavos que trabajan, y sólo se detiene en el momento en que ya no hay amos ni esclavos en el marco de un Estado universal y homogéneo que agota todas las posibilidades de reconocimiento y en el que se alcanza también un saber absoluto, es decir universal y necesario. Ciertamente la interpretación de Kojève es muy libre respecto de las verdaderas intenciones filosóficas de Hegel, pero eso es harina de otro costal, y de ello me ocupo en otro trabajo (De la Maza, 2012).

Siguiendo a Kojéve, Lacan sostiene que el deseo es humano en la medida que niega la naturalidad o necesidad animal y se refiere a un objeto no natural, que no se encuentra en la realidad dada. El objeto del deseo humano no puede ser, por tanto, otra cosa que el deseo mismo, el deseo desea el deseo del otro, que desemboca en la lucha a muerte por el simple prestigio.

En el origen, antes del lenguaje, el deseo sólo existe en el plano único de la relación imaginaria del estadio especular, existe proyectado, alienado en el otro. La tensión que provoca no tiene salida. Es decir que no tiene salida Hegel lo enseña- que la destrucción del otro.

En esta relación, el deseo del sujeto solo puede confirmarse en una competencia, en una rivalidad absoluta con el otro por el objeto hacia el cual tiende. Cada vez que nos aproximamos, en un sujeto, a esta alienación primordial, se genera la agresividad más radical: el deseo de la desaparición del otro, en tanto el otro soporta el deseo del sujeto. (Lacan, 1981a: 253ss.)

En un texto de 1948, "La agresividad en el psicoanálisis", Lacan sostenía que "Hegel había dado para siempre la teoría de la función propia de la agresividad en la ontología humana", y que de la dialéctica del amo y del esclavo en Hegel "se deduce todo el progreso subjetivo y objetivo de nuestra historia" (Lacan, 1971: 113). Por otra parte, Lacan comparte la identificación que la interpretación de Kojève, fuertemente influida por la filosofía de Martin Heidegger, establece entre la libertad y la muerte, o entre el dominio absoluto y la alteridad absoluta. Kojève afirmaba que la filosofía de Hegel es una filosofía de la muerte, puesto que sólo un ser mortal, radicalmente finito, puede ser libre, y Lacan agrega que la muerte es "el 
tercero esencial del progreso por donde el hombre se humaniza en la relación con su semejante". Pero de lo que se trata en la relación narcisista es "de la muerte imaginaria e imaginada" puesto que si se realizara el movimiento dialéctico se detendría por falta de combatientes. Y según Lacan, esta muerte imaginaria e imaginada se introduce también en la formación del neurótico e incluso hasta cierto punto en la "actitud existencial característica del hombre moderno" (Lacan, 2010: 50ss.; Hegel, 2010: 111-114).

El deseo del hombre como deseo del otro no tiene un sentido único, pues en ese caso solo habría la radical intolerancia entre las conciencias. En un segundo momento, que corresponde al tiempo del espejo, el deseo es realizado en el otro y por el otro. El sujeto integra la forma del yo, y el deseo del otro entra en la mediatización del lenguaje. El deseo es nombrado en el otro y por el otro, entrando en una relación simbólica del yo (je) y el tú, que es la relación del reconocimiento recíproco, y que corresponde a una ley preparada de antemano para incluir la historia de cada individuo (Lacan, 1971: 262ss.).

Desde la perspectiva de Lacan no existe el deseo de reconocimiento, sino solo la demanda de reconocimiento. La demanda es uno de los fines de las pulsiones narcisistas del sujeto, a saber, el de ser amado. El deseo es lo que persiste del movimiento del sujeto hacia el otro, de su demanda, una vez que se han satisfecho las necesidades. En ese sentido está más allá de la demanda. Pero también está más acá de ella, pues es menos "incondicional" que la demanda de amor:

El deseo se esboza en el margen donde la demanda se desgarra de la necesidad: margen que es el que la demanda, cuyo llamado no puede ser incondicional sino dirigido al Otro, abre bajo la forma de la falla posible que pueda aportarle la necesidad, por no tener satisfacción universal (lo que suele llamarse: angustia). (Lacan: 1975: 793)

La irreductibilidad del deseo a la demanda y a la necesidad es para Lacan una prueba de lo inadecuado de la crítica que se le ha hecho de degradar el psicoanálisis mediante una reducción logicizante como consecuencia del recurso a Hegel. Lacan concede que el deseo no es articulable en el caso particular de cada hombre, pero esto no significa que no esté articulado. Al contrario, si no es articulable es precisamente porque está articulado, es decir porque está vinculado a la presencia del significante en el hombre (Lacan, 1975: 784; 1999: 337ss.).

Ahora bien, si el ser humano se reconoce a sí mismo en el deseo del otro, entonces siempre está más allá de sí mismo, nunca es idéntico a sí mismo (Lacan, 1981: 222ss., 262, 325). Por lo tanto, no puede ser representado sino en su ausencia, en Otro lugar, que es el lenguaje. El sujeto se 
hace representar por medio de un significante ante otro significante, sin poder jamás comprenderse de un modo plenamente presente como significado.

\section{EL LENGUAJE}

En un texto de texto 1936, que lleva por título "Más allá del 'principio de realidad"" se revela ya la presencia determinante del pensamiento de Hegel a propósito de la función del lenguaje en el psicoanálisis. Lacan sostiene que el lenguaje no tiene por función representar la realidad o comunicar un sentido preexistente al decir, sino representar, en el decir mismo, a un sujeto reducido al hecho de hablar. Por lo tanto, el análisis no trata de determinar una realidad, sino de realizar la verdad del sujeto en tanto que certeza inherente al hecho de hablar, separada de la noción de realidad.

Como lo hace ver Mikkel Borch-Jacobbsen en Lacan con los filósofos (Biblioteca del Colegio Internacional de Filosofía, 1997: 278ss.; ver también Borch-Jacobbsen, 1995), Lacan reinterpreta, en este contexto, el cogito cartesiano en términos hegelianos, que implican la mediación de la palabra. El sujeto debe decirse en honor de otro, porque no puede acceder a la plena conciencia de sí mismo más que enajenándose de sí en un lenguaje común y haciéndose reconocer por otros en un espacio abierto común. Esta autoexteriorización en la palabra equivale a la exteriorización de la propia imagen en un espejo o la identificación con otro yo especular, a través de la cual, según Lacan, se constituye el yo. Por ello el yo no puede verse más que distanciado de sí mismo, es decir enajenado o ausente de sí.

El punto de partida inicial de Lacan, basado en la intersubjetividad interpretada al modo de Hegel-Kojève, se relativiza en la medida que aumenta la influencia de Lévi-Strauss, quien presenta a fines de los años '40, una teoría sobre la eficacia simbólica del lenguaje que él mismo relaciona con la fuente de la eficacia de las palabras en el psicoanálisis. Lévi-Strauss propone retrotraer la articulación del sentido desde el ámbito de la experiencia vivida a la estructura sintáctica de los sistemas de lenguaje que operarían de un modo inconsciente por medio de la función simbólica. Bajo su influencia, Lacan asocia los aspectos semánticos del lenguaje, vale decir el efecto de significación, al registro imaginario donde se realiza la experiencia vivida, para luego mostrar la dependencia de éste, en cuanto virtualidad emergente, del registro simbólico, entendido como ordenación sintáctica de la articulación significante.

El valor de lo simbólico es en Lacan inversamente proporcional al valor de la conciencia en lo imaginario. Mientras la conciencia es asignada a lo imaginario, lo inconsciente en Lacan depende de lo simbólico. En este sentido Lacan polemiza con la psicología americana del ego, introducida 
por autores como Hartmann, Loewenstein y Kris, y consolidada en el movimiento psicoanalítico después de 1945 bajo la influencia de los estudios sobre la infancia de Ana Freud (Lacan, 1971: 471, 631; 2012: 224). Según Lacan, este enfoque se caracteriza por el desconocimiento del inconsciente y del poder de la palabra, sacrificando el sujeto del inconsciente al yo objetivado.

Con el concepto del orden simbólico Lacan se hace cargo de la concepción freudiana del complejo de Edipo, transformándolo en un fenómeno lingüístico al que caracteriza como el descubrimiento, por parte del sujeto, del Nombre del Padre, en virtud del cual la relación imaginaria con la imagen del padre físico se convierte en una abstracción mayor del rol del padre como poseedor de la madre y el lugar de la Ley.

Según Lacan, el objeto pasa al plano de lenguaje con los primeros juegos de los niños. De modo casi natural e imperceptible emerge el símbolo y se vuelve más importante que el objeto. De ese modo, la palabra o el concepto se convierte en la cosa misma, lo que puede ser relacionado con la Fenomenología del espiritu y la Lógica de Hegel, en el sentido de que en ellas se identifican el concepto y el ser (Lacan, 1981: 351ss.; Hegel, 2011: Introducción). Lacan refuerza esta idea recordando, por ejemplo, la afirmación hegeliana de que el concepto es el tiempo que está ahî" (Hegel, 2010: 429). Lacan dice: "El concepto es el tiempo de la cosa" (Lacan, 2005a: 43), lo que a su juicio equivale a sostener que el concepto está allí donde la cosa no está, llega para reemplazarla, hace que la cosa esté allí, aun no estando allí:

Porque la palabra elefante existe en la lengua de los hombres, el elefante ha entrado en sus deliberaciones, los hombres pudieron tomar respecto de ellos, incluso antes de tocarlos, resoluciones mucho más decisivas para estos paquidermos que cualquier otra cosa ocurrida en su historia; el cruce de un río o la esterilización natural de un bosque. Solo con la palabra elefante y el modo en que la utilizan los hombres, les ocurren a los elefantes cosas, favorables o desfavorables, fastas o nefastas, pero de todos modos catastróficas, antes incluso de que se haya alzado hacia ellos un arco o un fusil. (Lacan, 1981: 264)

La importancia del lenguaje en la filosofía de Hegel fue especialmente destacada por la interpretación de Jean Hyppolite, no menos importante para Lacan que Kojêve. Si bien en una etapa inicial de su pensamiento Hyppolite fue influido por la lectura antropologizante de Kojève, es posible advertir un cambio de orientación en la interpretación de la autoconciencia desde la centralidad de la dialéctica del amo y el esclavo hacia un 
enfoque marcado por el lenguaje. En su comentario de 1946, Génesis y estructura de la fenomenología del espiritu, sostiene que el principal interés de la filosofía de Hegel y de la Fenomenología en particular es el esfuerzo por unir lo universal y lo particular en la unidad espiritual (Hyppolite, 1974: 48). La tarea de la Fenomenología es permitir que la conciencia individual finita capte el sentido universal de su tiempo y que, al mismo tiempo, y por ello mismo se eleve hasta un saber absoluto que sobrepase todo tiempo. Y en su libro titulado Lógica y existencia, Hyppolite afirma que el reconocimiento mutuo de las conciencias, que es el elemento fundamental del saber absoluto, se realiza en el elemento del lenguaje, por lo que el nexo entre lo singular y lo universal es el concepto. El silencio o el aislamiento conducen a la disolución y la locura:

Es necesario confesar su acción, la manera particular de ser en el mundo, para conquistar su universalidad, para hacerla reconocer. Es necesario también acoger en sí la determinación particular del otro para elevarla a la universalidad, para promover a esta universalidad concreta, que es la unidad verdadera de lo singular y lo universal [...]. (Hyppolite, 1987: 28)

Lacan, por su parte, sostiene que el significante no significa en sí mismo nada en particular, aparte del hecho mismo de la significación, según las conexiones que establece con otros significantes. No es un signo, ni manifiesta nada más que la diferencia como tal.

Técnicamente, llamamos significante a lo que se traduce. Se trata de un elemento que presenta estas dos dimensiones: está ligado sincrónicamente a un batería de otros elementos por los que se puede sustituir, y, por otra parte, está disponible para un uso diacrónico, es decir, para la constitución de una cadena significante. (Lacan, 2005b: 24)

Siguiendo la interpretación del lingüista Roman Jakobson, Lacan llama metonimia a la dimensión del significante según la cual toda nueva significación surge de la modificación de significantes de uso anterior ya aceptado, y por lo tanto participa de significaciones anteriores, aunque sean muy extrañas al nuevo empleo que se le asigne. La metonimia presupone, como en Jakobson, la metáfora, que consiste en la sustitución de un significante por otro, de la que depende el surgimiento de toda nueva significación. (Lacan, 2005b: 26) De estas dimensiones del significante se derivan, según Lacan, importantes consecuencias para la constitución de la subjetividad. 


\section{EL SUJETO}

Sin compartir la concepción hegeliana acerca del saber absoluto, y aceptando solo parcialmente la conexión entre concepto y ser, la reflexión de Lacan sobre el significante está en permanente interrelación con su reflexión sobre el sujeto. En su Seminario 1 distingue uso del lenguaje como enganche con el otro, o como mediación propia de lo imaginario, del uso del lenguaje como revelación del ser, que corresponde a su vertiente simbólica. Este último uso se da, por ejemplo, en la función nominal del lenguaje. La adquisición de un nombre transforma por completo la posición de un sujeto en medio de las cosas, haciéndolo pasar propiamente al estado humano (Lacan, 1981a: libro I). Los sustantivos liberan del aquí y ahora de lo imaginario, de la inmediatez de la situación familiar y de lo presimbólico en general, pues introducen una separación respecto de los aspectos biológicos, como ocurre, por ejemplo, con la función paterna respecto del padre biológico. Los pronombres son el lugar del surgimiento del inconsciente. La primera persona resulta en una división (Spaltung) del sujeto, en virtud del cual el sujeto es designado por el yo, pero al mismo tiempo excluido del significante que lo determina. El sujeto "mediatizado" por el lenguaje se encuentra irremediablemente dividido, porque se halla excluido de la cadena significante al mismo tiempo que está "representado" en ella. El inconsciente es la realidad alienada y reprimida del sujeto en el proceso por el cual, al recibir un nombre, es transformado en una representación de sí mismo, y se produce por medio de la represión primaria que consiste justamente en la adquisición del lenguaje.

El sujeto es un espacio vacío, una "discontinuidad en lo real", algo que no existe y que sólo se puede poner después del uso del lenguaje. Para llegar a la existencia tiene que subordinarse a los significantes, haciéndose cargo de sus carencias. Lacan celebra el tratamiento que Hegel hace en la Fenomenología del espiritu de la "ley del corazón" y el "delirio de la infatuación" como formas de locura asociadas al "alma bella", que "no reconoce la razón misma de su ser en el desorden que denuncia en el mundo", y que permanecen enredadas en la trampa ofrecida por el espejismo al yo.

[...] el loco quiere imponer la ley de su corazón a lo que se le presenta como el desorden del mundo, empresa 'insensata', pero no en el sentido de que es una falta de adaptación a la vida [...], más bien por el hecho de que el sujeto no reconoce en el desorden del mundo la manifestación misma de su ser actual, y porque lo que experimenta como ley de su corazón no es más que la imagen invertida, tanto como virtual, de ese mismo ser. (Lacan, 1971: 162; ver también $270,397,457$ ) 
La ley del corazón corresponde, según Hegel, al individuo que se opone a la sociedad mediante una crítica que no cambia nada en ella, y está en la contradicción de vivir de hecho en y por el orden que critica. El delirio de la infatuación, por su parte, consiste en denunciar la perversión del mundo de los hombres como algo introducido por otras individualidades distintas de ella, que se considera a sí misma superior, sin advertir que el orden del mundo es un orden estable y universal en el que se encuentran vinculados entre sí todos los corazones, sin que ninguno en particular pueda alterarlo (Hegel, 2010: 202-207).

El problema de la relación entre el sujeto que está más allá del yo con el significante que lo determina es abordado por Lacan con su lectura del cuento "La carta robada" de Edgar Allan Poe. La carta comprometedora que un desconocido dirige a la reina y que sufre un desvío, representa al significante, en torno al cual se ordenan tres miradas diferentes: la de los que no ven nada: el rey y la policía; la de los que ven que la primera mirada no ve nada y se engañan creyendo que lo que se esconde está cubierto: la reina primero, y después el ministro; la de los que descubren lo escondido de lo que otros quieren apoderarse: primero el ministro y finalmente Arsenio Dupin. Durante el transcurso del relato los personajes cambian de lugar. Por ejemplo, el ministro toma la carta, pero Dupin se la birla y toma su posición, y el ministro se traslada a la posición de la reina. Pero estos cambios de posición ejercen un poder estructurador sobre los individuos que las ocupan, aun cuando nunca se de a conocer el contenido de la carta, es decir del significante. Lacan relaciona esta narración con el descubrimiento freudiano del automatismo de repetición (Wiederholungszwang):

Si lo que Freud descubrió y redescubre de manera cada vez más abierta tiene un sentido, es que el desplazamiento del significante determina a los sujetos en sus actos, en su destino, en sus rechazos, en sus cegueras, en sus éxitos y en su suerte, a despecho de sus dotes innatas y de su logro social, sin consideración del carácter o el sexo, y que de buena o mala gana seguirá al tren del significante como armas y bagajes, todo lo dado de lo psicológico. (Lacan, 1971: 24)

El lenguaje presenta la ausencia del sujeto que se dice en él "aniquilando" toda realidad, incluso la suya. En este sentido, Lacan invierte la concepción moderna del sujeto. No es el sujeto quien conoce el mundo y construye la verdad, a la que describe en un saber, sino que la verdad y los significantes construyen al sujeto desde sí mismos. La distancia insuperable entre el significante y el significado hace que el sujeto no sea solo sujeto del significado, sino también, y, sobre todo, sujeto del significante. 
Lacan dedica numerosas reflexiones al cogito cartesiano, que apuntan a mostrar que la idea filosófica tradicional del sujeto es insostenible, y debe ser reemplazada por el sujeto que solo existe como efecto del significante. Destaca el hecho de que el cogito cartesiano instaura el rechazo al modo como tradicionalmente la filosofía se había ocupado del ser y con ello instaura la ciencia misma. Una vez que en su primera Meditación Metafísica ha renunciado a todas las formas tradicionales del saber, termina reconociendo que para realizar esta negación es necesario que yo (je) sea yo (moi), es decir un sujeto imaginario. El cogito o yo pienso resulta del vaciamiento de todo lo que yo soy: "Pienso donde no soy, luego soy donde no pienso" (Lacan, 1971: 498). En lugar del ente tradicional que manifestaba el ser queda un conjunto vacío.

La promoción de la conciencia como esencial al sujeto en la secuela histórica del cogito cartesiano es para nosotros la acentuación engañosa de la transparencia del Yo $[j e]$ en acto a expensas de la opacidad del significante que lo determina, y el deslizamiento por el cual el Bewusstsein sirve para cubrir la confusión del Selbst, viene precisamente a demostrar, en la Fenomenología del espiritu, por el rigor de Hegel, la razón de su error. (Lacan, 1975: 789)

Lo que piensa en lugar del sujeto, en el lugar que éste no puede ocupar y desde el cual se plantea la pregunta por él, es, según Lacan, el Otro con mayúscula. El Otro que Lacan pone en el centro de la dialéctica del reconocimiento y el deseo es un nuevo Amo, pues el sujeto no sólo es profundamente dependiente del Otro, sino que es completamente relativo a él. Reformulando a Hegel, Lacan hace depender la identidad del sujeto de la mediación del Otro, es decir del conjunto de los significantes que lo modelan. Por lo mismo, define el inconsciente como "el discurso del Otro" (Lacan, 1971: 254).

Según Jacques-Alain Miller, en Lacan hay una correlación inversa entre el Otro y el sujeto. El Otro crece progresivamente, y mientras más crece, más se reduce el sujeto, hasta llegar a ser un mero agujero. En el Seminario 2 (Lacan, 1983) el Otro es Otro sujeto. En el Seminario 5 (Lacan, 1999) es el lugar del código, que se torna un lugar simbólico, abstracto, supraindividual. Finalmente se vuelve el cuerpo de la cultura, del saber, el lugar de las estructuras de parentesco, de la metáfora paterna, del orden del discurso, de la norma social. Puede confundirse tanto con el Dios de los filósofos como con el Dios de Abrahám. Es una suerte de enorme englobante, que implica casi todo, menos el sujeto. Puede encarnarse en un ser (el padre, la madre, etc.) y estar lógicamente reducido a la articulación mínima de un significante con otro significante (Miller, 2011: 215218). 


\section{SABER Y VERDAD}

En el Discurso en el Congreso de Roma de 1953, Lacan señalaba que los principios que gobiernan la experiencia psicoanalítica en la práctica de Freud "no son otra cosa que la dialéctica de la conciencia de sí, tal como se realiza de Sócrates a Hegel, a partir de la suposición irónica de que todo lo que es racional es real para precipitarse en el juicio científico de que todo lo que es real es racional" (Lacan, 1971: 280ss. Lacan cita expresamente el Prefacio de la Filosofía del Derecho de Hegel, 2017a: 17).

En el Seminario 2, Lacan sostiene que "con Hegel, y sin saberlo, en la medida que todo el mundo es hegeliano sin saberlo, hemos llevado sumamente lejos la identificación del hombre con su saber, que es un saber acumulado" (Lacan, 1983: 116). La concepción hegeliana del saber absoluto es, dice Lacan, "ese momento en que la totalidad del discurso se cierra sobre sí mismo en una no contradicción perfecta hasta el punto de $-\mathrm{y}$ precisamente por- plantearse, explicarse y justificarse" (Lacan, 1981: 384).

Lacan considera que ese ideal es por principio inalcanzable, pues la experiencia psicoanalítica demuestra que la verdad se encuentra inseparablemente unida al error, como su encarnación habitual, sin la cual esta no sería posible. Por otra parte, dialogando con Jean Hyppolite acerca del concepto hegeliano del saber absoluto y de la dialéctica de la conciencia, sostiene que el saber absoluto hegeliano no solo se encarna en un discurso coherente y justificado en el que toda la historia está siempre actualmente presente, sino que además es concebido como propiedad de los que saben y como instrumento de poder. Sin embargo, cuando prende la aspiración de dominio se produce inevitablemente la alienación recíproca entre dominadores y dominados, que el propio Hegel ha puesto en evidencia al exponer que la realidad de cada ser humano está en el ser del otro. Según Lacan, Freud muestra una salida de esta situación al descubrir que el hombre no está completamente en el hombre, es decir al desbordar los límites de la antropología y entrar en el dominio de lo simbólico, sometido a la compulsión de repetición, y como tal comparable al circuito integrado de una máquina de calcular (Lacan, 1983: 113-142).

En "Subversión del sujeto y dialéctica del deseo", de 1960, Lacan afirma que el aporte freudiano a la cultura radica en mostrar cómo su experiencia remite a un concepto de sujeto que conlleva un distanciamiento de la unión entre la verdad y el saber (Lacan, 1975: 773-784). El alejamiento respecto de la concepción hegeliana del saber se puede apreciar claramente hacia 1962-3 en el Seminario 10 (Lacan, 2006) sobre la Angustia y en la única lección del Seminario sobre el Nombre del Padre, del 20 de noviembre de 1963. En esta última lección afirma que los primeros pasos 
de su enseñanza "avanzaron por el sendero de la dialéctica hegeliana", como "etapa necesaria para abrir una brecha en el mundo de la positividad"; pero junto con reconocerle el aporte a superar la oposición entre lo universal y lo particular, Lacan declara que esta dialéctica es falsa, por contradecir el testimonio de las ciencias naturales y el progreso de las matemáticas, pero también por la percepción de la angustia como testimonio de una hiancia existencial, detectada primero por Kierkegaard en abierta oposición a Hegel y esclarecida posteriormente por Freud (Lacan, 2005a: 73ss.).

Lacan sostiene, en el Seminario 10, que tiene en común con Hegel lo que denomina el "objeto $a$ " afectado por el deseo en un momento en que el proceso de la autoconciencia se ve marcado por la finitud al limitarse mutuamente las autoconciencias enfrentadas (Lacan, 2006: 35). El "objeto a" es como un residuo u desecho irreductible a lo simbólico que no tiene originalmente nada que ver con el objeto de la percepción y el conocimiento ni es simplemente el objeto del deseo. Pertenece a lo imaginario, y es más bien una falta en forma de objeto, la causa del deseo que está más allá del objeto deseado, pues el objeto no está a la altura de la expectativa que despierta. En este sentido, el objeto presenta un vacío en su centro. Según Lacan, la angustia revela el carácter parcial y falso de la fórmula hegeliana, debido a su punto de partida demasiado centrado en lo imaginario, que no permite otra mediación que la de la violencia, a diferencia del sentido lacaniano del deseo, que es mucho más abierta a otra forma de mediación, como lo es la mediación simbólica.

En el sentido hegeliano, el deseo de deseo es deseo de un deseo que responde a la llamada del sujeto. Es deseo de un deseante [...] ¿Qué significa esto? Que el Otro instituirá algo, designado por $a$, que es de lo que se trata en el plano de aquello que desea. Ahí está todo el obstáculo. Al exigir ser reconocido, allí donde soy reconocido, no soy reconocido sino como objeto [...] y no puedo soportarme como objeto, puesto que dicho objeto que soy es en su esencia una conciencia, una Selbst-bewnusstsein. [...] Es preciso, pues, a toda costa, decidir entre nuestras dos conciencias. Ya no hay más mediación que la violencia. Tal es la suerte del deseo en Hegel. (Lacan, 2006: 33)

En el Seminario 17 (Lacan, 2001), Lacan desarrolla una nueva versión de su pensamiento, mediante la teoría de los cuatro discursos. El concepto de discurso no se refiere aquí primariamente a los intercambios verbales entre individuos, sino a una relación estructural entre cuatro términos (S1: significante del amo, S2: el saber, \$: el sujeto del lenguaje, el “objeto a”), que en diversos ámbitos se relacionan distintamente entre sí. El intercambio de los términos hace que surja un discurso distinto en cada caso: el 
discurso del amo, el discurso de la histeria, el discurso del análisis y finalmente el discurso universitario (Laurent, 1992).

S1, el amo, es un significante necesario para mantener unido el conjunto de los significantes. Como tal no tiene significado, sino que es la cópula entre los distintos miembros y se constituye en el instaurador, por medio del cual se hace posible la existencia del sujeto, que se determina por medio de los significantes. Marca el lugar del elemento singular (o unario) que genera todas las significaciones, y desde el cual se ramifica todo el sistema del lenguaje y de las significaciones, el sistema de los significantes binarios que remiten a otros significantes: S2, el saber.

Ahora bien, el discurso del amo es una reformulación de la dialéctica del amo y del esclavo, en la que el amo, que es el que ha preferido enfrentar la muerte a perder su independencia, deja el trabajo al esclavo. Según Lacan, lo que se trasmite desde el esclavo al amo es el saber articulado como episteme. La función histórica de la filosofía sería "esta extracción, casi diría esta traición, del saber del esclavo para conseguir convertirlo en saber de amo" (Lacan, 2001: 21). Pero ese saber del amo extraído al esclavo es un saber que no puede alcanzar lo que pretende, y Lacan invoca justamente a Hegel para ponerlo de manifiesto, pero al mismo tiempo para mostrar, contra Hegel, la imposibilidad de un saber absoluto.

La ciencia quiere producir un saber objetivo, una verdad que tenga validez para todo sujeto. Su meta es que el "objeto a" sea completamente asumido por el mundo de los significantes, de modo que todo pueda ser dicho y explicado científicamente.

En el fondo, el "objeto a" no tiene nada que ver con el objeto de la ciencia propiamente tal, pero al exponer el objeto de la ciencia, Lacan lo pone cerca del "objeto a", puesto que la ciencia no se puede ocupar nunca de las cosas en sí, sino sólo con imágenes de las cosas.

Para Lacan la verdad no es algo que tiene que ser descubierto y construido por la actividad investigadora del sujeto que desea conocer, sino que nos precede, pertenece a lo real y se expresa en las categorías de lo simbólico y de lo imaginario. Pero lo real mismo permanece por definición inalcanzable, es aquello que siempre está en su lugar, en forma completa y sin fisuras. La objetividad, como automanifestación de las cosas mismas, no es posible, dado que el sujeto de la ciencia no es eliminable y las cosas no pueden hablar. Por eso, la verdad sólo se deja decir a medias:

Si hay algo que todo nuestro abordaje delimita y que con toda seguridad ha sido renovado por la experiencia analítica, es que no puede hacerse ninguna referencia a la verdad sin indicar que únicamente es accesible a un medio decir, que no puede decirse por completo, porque más allá de esta mitad no 
hay nada que decir. Esto es todo lo que puede decirse. Aquí, en consecuencia, el discurso queda abolido. (Lacan, 2001: 54)

A partir de la negación de que el trabajo del esclavo, tal como lo articula Hegel, pueda engendrar un saber absoluto o cualquier forma de saber a través del camino de la formación cultural, Lacan introduce el concepto del plus de goce. Lo que le interesa es mantener la verdad fuera del alcance del sistema y constituir un mundo en el cual ella no tiene lugar. En este sentido dice que la verdad es hermana del goce. Lo propio del goce es justamente el ser extraído del mundo. En tanto que es definido como prohibido al hablante como tal, es una posibilidad fuera del universo del discurso. La verdad, rechazada del mundo, hace su retorno solamente en valores de verdad, como en la lógica simbólica. Lo que queda del goce es un plus del goce, un residuo irreductible a toda descarga simbólica. De lo que no se puede recuperar en la experiencia de la repetición, queda sólo la plusvalía del goce, del mismo modo que, en el sistema marxista, el trabajador no puede recuperar el valor del trabajo y lo que queda es la plusvalía (Lacan, 2001: 84).

\section{CONCLUSIÓN}

Para concluir podemos afirmar, como adelantara en la introducción a esta ponencia, que el aporte que Hegel hace a Lacan se relaciona en primer lugar con la teoría de este último sobre el surgimiento del yo y el modo de funcionamiento de la región psíquica, que a partir de sus primeros escritos denomina como "imaginaria". En segundo lugar, Lacan obtiene de Hegel, en parte a través de Kojève, pero quizás más decisivamente por la influencia de Jean Hyppolite, una noción del lenguaje como articulación de lo universal y lo particular que determina la constitución del sujeto como efecto de las palabras. Con estas herramientas aportadas por Hegel, Lacan podía enfrentar las pretensiones, a su juicio ilusorias, de la psicología americana del yo. Pero junto con asumir a su manera la teoría de la intersubjetividad y del lenguaje de Hegel, Lacan tiene muy claro su profundo desacuerdo con la concepción del saber absoluto, en la medida que este implica dar cuenta de la realidad sin residuos. La concepción lacaniana de lo real lo presenta como irreductible a la simbolización, y por lo tanto es incompatible con un sistema de la ciencia, concebido al modo de Hegel.

\section{REFERENCIAS}

Biblioteca del Colegio Internacional de Filosofía (1997). Lacan con los filósofos. México: Siglo XXI. 
Borch-Jacobsen, M. (1995). Lacan. El amo absoluto. Buenos Aires: Amorrortu.

De la Maza, L. M. (2012). La interpretación antropológica de la Fenomenología del Espíritu. Aportes y problemas. Revista de Filosofía, 68, 79-101.

Hegel, G. W. F. (2010). Fenomenología del espíritu. Madrid: UAM/Abada.

Hegel, G. W. F. (2011). Ciencia de la Lógica. I. La Lógica Objetiva. Madrid: UAM/Abada.

Hegel, G. W. F. (2017a). Fundamentos de la filosofía del derecho o Compendio de Derecho Naturaly Ciencia Politica. Madrid: Tecnos.

Hegel, G. W. F. (2017b). Enciclopedia de las ciencias filosóficas. Madrid: UAM/Abada. Hyppolitte, J. (1974). Génesis y estructura de la Fenomenología del espiritu. Barcelona: Península.

Hyppolitte, J. (1987). Lógica y existencia. Ensayo sobre la lógica de Hegel. Puebla: Universidad Autónoma de Puebla.

Kojève, A. (2013). Introducción a la lectura de Hegel. Madrid: Trotta.

Labarrière, P.-J. \& Jarczyk, G. (1996). De Kojève a Hegel, cent cincuante ans de pensée bégéelianne en France. Paris: Albin.

Lacan, J. (1971). Escritos (vol. 1). Buenos Aires: Siglo XXI.

Lacan, J. (1975). Escritos (vol. 2). Buenos Aires: Siglo XXI.

Lacan, J. (1981). El Seminario de Jacques Lacan. Libro 1: Los escritos técnicos de Freud. Buenos Aires: Paidós.

Lacan, J. (1983). El Seminario de Jacques Lacan. Libro 2: El yo en la teoría de Freudy en la técnica psicoanalítica. Buenos Aires: Paidós.

Lacan, J. (1999). El Seminario de Jacques Lacan. Libro 5: Las formaciones del inconsciente. Buenos Aires: Paidós.

Lacan, J. (2001). El Seminario de Jacques Lacan. Libro 11: Los cuatro conceptos fundamentales del psicoanálisis. Buenos Aires: Paidós.

Lacan, J. (2005a). De los nombres del Padre. Buenos Aires: Paidós.

Lacan, J. (2005b). El triunfo de la religión. Precedido de Discurso a los católicos. Buenos Aires: Paidós.

Lacan, J. (2006). El Seminario de Jacques Lacan. Libro 10: La Angustia. Buenos Aires: Paidós.

Lacan, J. (2010). El mito individual del neurótico o Poesía y verdad en la neurosis. Buenos Aires: Paidós.

Lacan, J. (2012). Otros Escritos. Buenos Aires: Paidós.

Laurent, E. (1992). Lacan y los discursos. Buenos Aires: Manantial.

Miller, J.-A. (2011). La experiencia de lo real en la cura psicoanalítica. Buenos Aires: Paidós.

Sumario: 1. Las trampas de lo imaginario; 2. El deseo de deseo; 3. El lenguaje; 4. El sujeto; 5. Saber y verdad; Conclusión; Referencias. 